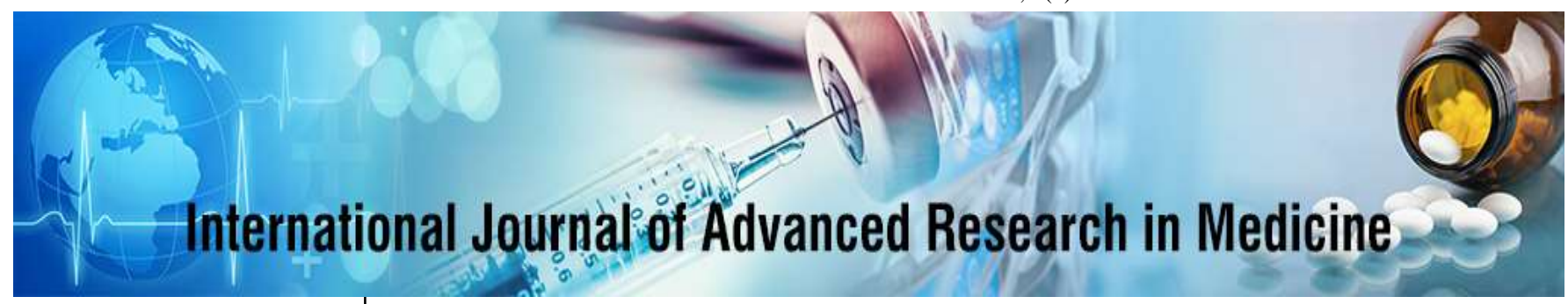

E-ISSN: 2706-9575

P-ISSN: 2706-9567

IJARM 2021; 3(1): 314-317

Received: 11-12-2020

Accepted: 02-01-2021

Dr. Shreesh Kadur JM

Orthopaedic Surgeon, Sky Super Speciality Hospital, Iritty, Kannur, Kerala, India

Dr. Sharvani S

Senior Resident, Kodagu Institute of Medical Sciences, Madikeri, Karnataka, India

Corresponding Author:

Dr. Sharvani S

Senior Resident, Kodagu Institute of Medical Sciences, Madikeri, Karnataka, India

\section{Association of serum calcium, phosphrous and parathyroid hormone with cardiac abnormality in CKD patients: A pilot study}

\author{
Dr. Shreesh Kadur JM and Dr. Sharvani S
}

DOI: https://doi.org/10.22271/27069567.2021.v3.i1f.155

\begin{abstract}
Chronic kidney disease is commonly associated with increase in blood phosphate levels. In early stages phosphate levels are maintained in normal limits because of the hyperparathyroidism causing phosphaturia. With advancement in renal disease hyperphosphatemia becomes evident. As a consequence of same there will be worsening of hyperparathyroidism and predisposition to develop metastatic calcification. In this study we have analyzed the serum levels of Calcium, Phosphorous and Parathormone levels in chronic kidney disease patients who were evaluated in nephrourology centre over a period of one month. It was then evaluated to see the correlation between aforementioned parameters with cardiovascular disease in those patients. The study showed significant correlation between the serum phosphate levels with cardiovascular morbidity in study population but didn't show significant relation with serum calcium and parathormone levels. From the study it can be concluded that a large percentage of end stage renal disease patients have high phosphate levels and this plays a significant role in cardiovascular morbidity in them.
\end{abstract}

Keywords: Chronic kidney disease, phosphorous, parathyroid hormone, cardiovascular morbidity

\section{Introduction}

Chronic renal failure (CRF) is an irreversible decline of renal function which finally leads to end-stage renal disease (ESRD). This condition is associated with renal replacement therapy including dialysis or transplantation ${ }^{[1]}$. The annual rate of mortality from cardiovascular diseases in hemodialysis patients is around $9 \%$, which is 30 times higher than that in general population ${ }^{[2]}$. Ischemic heart diseases, atherosclerosis, myocardial dysfunction followed by heart failure, left ventricular hypertrophy and calcification of the heart valves are common diseases in haemodialysis patients ${ }^{[1,2]}$. The progress of chronic kidney disease leads to the development of hyperphosphatemia. Hyperphosphatemia reduces serum levels of calcium via making a connection between calcium and phosphate and chronically inhibiting renal alpha-hydroxylase activity and reducing the synthesis of 1,25-dihydroxyvitamin $\mathrm{D}$. The reduction of 1,25-dihydroxyvitamin $\mathrm{D}$ and calcium in the blood will stimulate the parathyroid gland to secrete the parathyroid hormone ${ }^{[3]}$. A link between secondary hyperparathyroidism and cardiovascular disease in dialysis patients has been suspected for a while now ${ }^{[1,4]}$. High levels of parathyroid hormones as seen in chronic kidney disease patients seem to damage the cardiac myocytes possible mechanism being calcium ionophore effect ${ }^{[5]}$. Few animal studies have demonstrated Parathyroid hormone as a permissive factor in development of uremic cardiomyopathy ${ }^{[6]}$. The aim of our study is to find out the prevelance of cardiac abnormalities in ckd patients and to associate the levels of calcium, phosphorous and PTH with the same.

\section{Materials and Methods}

The study was done in a tertiary nephro-urology care centre in Bangalore. Study was designed on cross sectional basis. Based on retrospective data over a period of three months observed in a month approximately 60 new cases got registered for evaluation of CKD. After considering of inclusion and exclusion criteria 50 was taken as sample size. Age $>18$ years with history of CKD were the inclusion criteria. Patients with prior history of cardiac abnormalities were excluded from the study. 
Two groups 2 groups each for assessing calcium $(\geq 11$ $\mathrm{mg} / \mathrm{dl},<11 \mathrm{mg} / \mathrm{dl})$, phosphorous $(\geq 5.5 \mathrm{mg} / \mathrm{dl},<5.5 \mathrm{mg} / \mathrm{dl})$ and PTH $(\geq 300 \mathrm{pg} / \mathrm{ml},<300 \mathrm{pg} / \mathrm{ml})$ with respect to prevalence of cardiac abnormalities were made. Results were tabulated and evaluated using SSPS 19 version software. All results are expressed as mean and standard deviation (SD). $\mathrm{P}$ value below 0.05 was considered significant.

\section{Results}

The study involving 50 patients had equal number of male and females. Mean age of the patient was $46.12 \pm 13.74 \mathrm{yrs}$. Diabetic kidney disease was the leading cause $(48 \%)$ followed by chronic glomerulonephritis (14\%). (Table 1) (Figure 1).

Table 1: Etiology of CKD in study population

\begin{tabular}{|c|c|c|}
\hline Cause Of Ckd & Number Of Cases & Percentage \\
\hline Diabetic kidney disease & 24 & $48 \%$ \\
\hline Chronic glomerulonephritis & 7 & $14 \%$ \\
\hline ADPKD & 1 & $12 \%$ \\
\hline IgA nephropathy & 6 & $2 \%$ \\
\hline Others (Lupus nephritis, Interstitial nephritis) & 12 & $24 \%$ \\
\hline
\end{tabular}

Among the cardiac abnormalities in CKD, 22\% of patients had changes of hypertensive heart disease and diastolic dysfunction. Twenty percent of cases had Ischemic heart disease with systolic dysfunction. Calcific valves was present in $10 \%$ patients and valvular dysfunction in about $8 \%$ patients. (Table 2 ).
Among the calcium, phosphorous and PTH, serum phosphorous values $(>5.5 \mathrm{mg} / \mathrm{dl})$ showed significant relationship with cardiac abnormality $(\mathrm{p}<0.003)$. Calcium and PTH values were insignificant but elevated (Table 3, 4, 5).

Table 2: Types of cardiac abnormalities in study population

\begin{tabular}{|c|c|c|}
\hline Cardiac Dysfunction & Number Of Cases & Percentage \\
\hline HHD with diastolic dysfunction & 12 & $22 \%$ \\
\hline IHD with systolic dysfunction & 10 & $20 \%$ \\
\hline Calcified valves & 5 & $10 \%$ \\
\hline Valvular heart disease & 4 & $8 \%$ \\
\hline
\end{tabular}

Table 3: Phosphorus $(\mathrm{Ph})$ code * Cardiac dysfunction crosstabulation

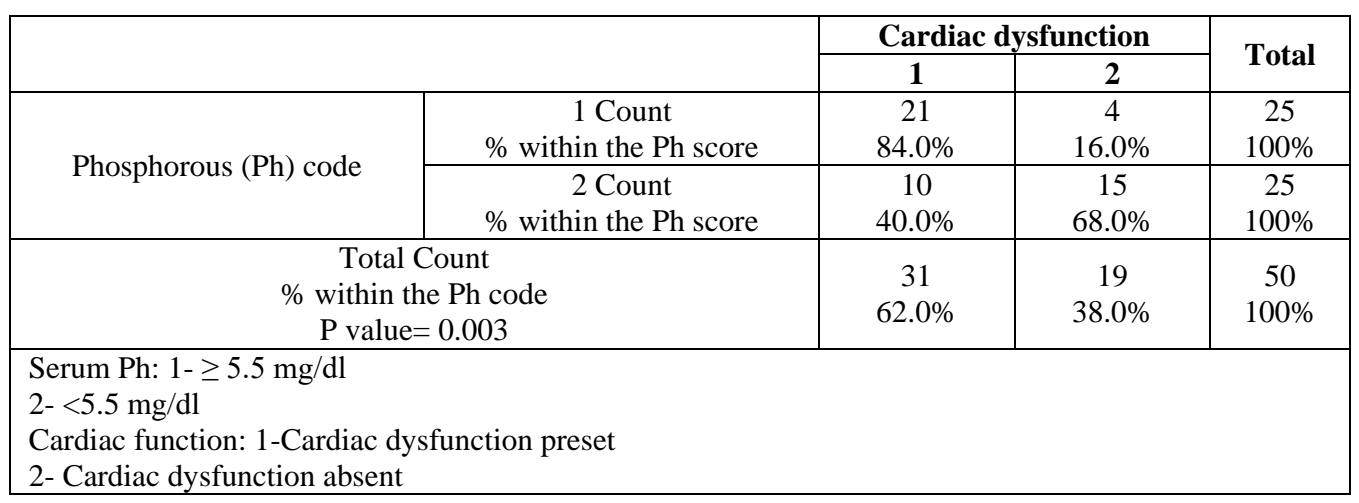

Table 4: Calcium $(\mathrm{Ca})$ code $*$ Cardiac dysfunction crosstabulation

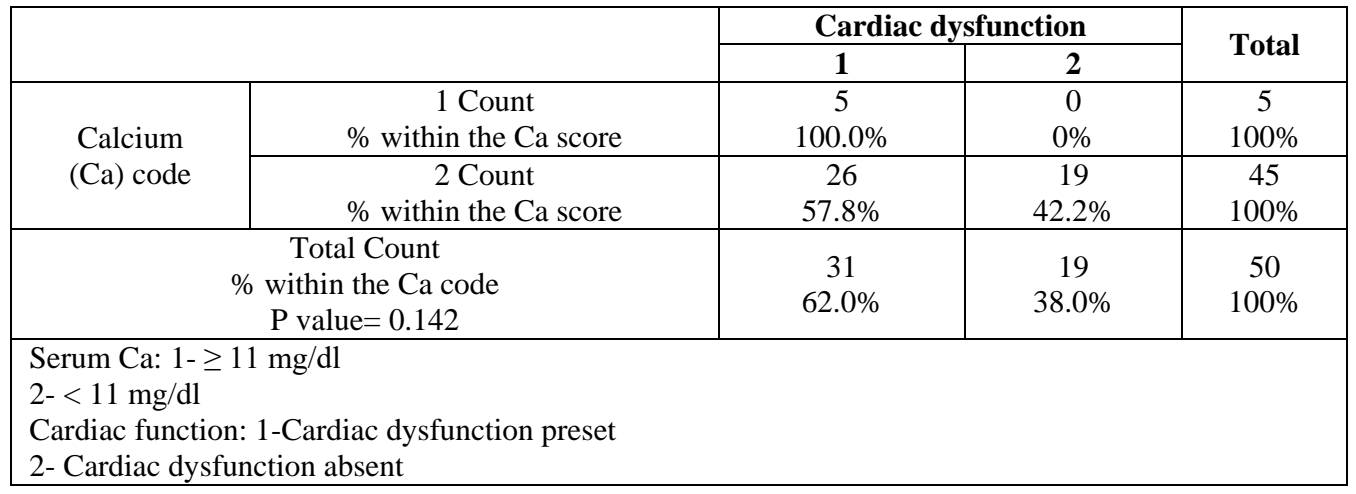


Table 5: PTH code * Cardiac dysfunction crosstabulation

\begin{tabular}{|c|c|c|c|c|}
\hline & \multicolumn{2}{|c|}{ Cardiac dysfunction } & \multirow{2}{*}{ Total } \\
\hline & & 1 & 2 & \\
\hline \multirow{2}{*}{ PTH code } & $\begin{array}{c}1 \text { Count } \\
\% \text { within the PTH score }\end{array}$ & $\begin{array}{c}14 \\
70 \%\end{array}$ & $\begin{array}{c}6 \\
30 \%\end{array}$ & $\begin{array}{c}20 \\
100 \%\end{array}$ \\
\hline & $\begin{array}{c}2 \text { Count } \\
\% \text { within the PTH score }\end{array}$ & $\begin{array}{c}16 \\
53.3 \% \\
\end{array}$ & $\begin{array}{c}14 \\
46.7 \% \\
\end{array}$ & $\begin{array}{c}30 \\
100 \% \\
\end{array}$ \\
\hline \multicolumn{2}{|c|}{$\begin{array}{c}\text { Total Count } \\
\% \text { within the PTH code } \\
\text { P value }=0.238\end{array}$} & $\begin{array}{c}30 \\
60 \%\end{array}$ & $\begin{array}{c}20 \\
40 \%\end{array}$ & $\begin{array}{c}50 \\
100 \%\end{array}$ \\
\hline \multicolumn{5}{|c|}{$\begin{array}{l}\text { Serum PTH: 1- >=300mg/dl } \\
2-<300 \mathrm{mg} / \mathrm{dl} \\
\text { Cardiac function: } 1 \text { - Cardiac dysfunction preset } \\
\text { 2- Cardiac dysfunction absent }\end{array}$} \\
\hline
\end{tabular}

\section{Discussion}

Cardiovascular diseases account for $40 \%-50 \%$ of mortality rate among end stage renal disease. Compared to general population, it accounts to 3 to 10 times more than that among healthy counterparts of the same age ${ }^{[7,8]}$.

In our study diabetic nephropathy (48\%) stands out as most common cause of CKD. An US popultion based study by Yelena et al [9] also showed prevalence of Diabetic nephropathy- $31 \%$ and glomerulonephritis - $13.7 \%$ as etiologies for CKD. Hypertensive heart disease with systolic dysfunction accounted for $22 \%$ of cases followed by IHD ( $20 \%$ ) and calcified valves $(10 \%)$.

A study conducted by Nematollahi et al. ${ }^{[10]}$ showed aortic valve calcification, mitral valve calcification, and mitral annulus calcification in $20 \%, 1 \%$, and $4 \%$ of hemodialysis patients, respectively. In another study conducted by Jalali et al. [11], mitral valve calcification and aortic valve calcification were observed in $3.9 \%$ and $1.9 \%$ respectively in hemodialysis patients. A study by Avila- Diaz et al. ${ }^{[12]}$ showed the prevalence of mitral valve calcification, aortic valve calcification and calcification of both valves in hemodialysis patients as $26.3 \% 57.8 \%$, and $15.8 \%$ respectively. In other studies, the calcification of the individual valve involvement were described separately, while in the present study we have reported collectively.

The frequent finding of hyperphosphatemia is due partly to the fact that phosphorus clearance by dialysis itself is not the major factor involved in the control of serum phosphorus ${ }^{[13-15]}$ Phosphate kinetic studies in hemodialysis patients show that there is an initially high phosphate clearance from the extracellular compartment followed by a slow efflux from an intracellular compartment ${ }^{[15-18]}$. In our study elevated serum phosphorous levels correlated with the cardiac abnormality whereas, calcium and PTH levels didn't. However serum PTH levels were elevated in $70 \%$ cases of CKD patients with cardiac abnormalities. Nematollahi et al. ${ }^{[10]}$ had found significant positive relationship with the calcification of the heart valves with serum phosphorous. He also found serum phosphorus level had a significant relationship with left ventricular systolic dysfunction. In the study of Mousavi- Movahed et al, ${ }^{[19]}$ no significant relationship between serum calcium and phosphorus levels with calcification of the heart valves was detected. However, the prevalence of hyperparathyroidism among hemodialysis patients was $77 \%$, which it had a significant relationship with calcification of the heart valves. Avila-Diaz et al. ${ }^{[12]}$ concluded that serum parathyroid hormone level was a major risk factor for the calcification of heart valves and had a direct relationship with valve calcification. The differences can be due to the therapeutic effects of medications given to the patients in various study groups as a part of CKD treatment.

In our study, we multiplied calcium by phosphorus in hemodialysis patients and the result was $40 \mathrm{mg}^{2} / \mathrm{dl}^{2}$. In a similar study by Nematollahi ${ }^{[10]}$ it was 44 units. The study of Block et al. ${ }^{[20]}$ inferred that every 10 units of $\mathrm{Ca} \times \mathrm{PO} 4$ product increase, the mortality rate of hemodialysis patients increased by $7 \%$.

\section{Conclusion}

Cardiac abnormalities are common in end stage renal disease patients. Metabolic abnormalities with calcium and phosphorous along with PTH are seen in these patients. Corealtion of metabolic abnormalities with cardiac disorder helps in predicting morbidity and mortality as cardiac disorders are one of causes of mortaliy in CKD patients. Whi calcium and PTH levels were non corelatiang, hyperphosphatemia can be inferred as risk factor for cardiac abnormalities present in CKD patients. Dietary restriction of phosphate can be helpful in reducing cardiovascular morbidity in CKD patient.

\section{Limitations}

It was a single population based study. Duration of dialysis or therapeutic medications were not considered. It was done as a pilot study hence the small sample size too.

\section{Conflict of Interest: None}

\section{Acknowledgments: None}

\section{References}

1. Voinescu A, Martin KJ. Calcium, Phosphate, PTH, Vitamin D and FGF-23 in Chronic Kidney Disease. In: Kalantar- Zadeh JD, ed. Nutritional Management of Renal Disease. 3rd ed. Academic Press 2013:263-83.

2. Li H, Wang S. Cardiovascular Disease in Hemodialysis Patients. InTech 2013.

3. Daugirdas JT, Blake PG, Ing TS. Handbook of Dialysis. 4th ed. Philadelphia: Lippincott Williams and Wilkins 2007.

4. Drueke T, Fauchet M, Fleury J, Lesourd P, Toure Y, Le Pailleur $\mathrm{C}$ et al. Effect of parathyroidectomy on leftventricular function in haemodialysis patients. Lancet 1980;1:112-114.

5. Parathyroid hormone increases cytosolic calcium concentration in adult rat cardiac myocytes. Am J Physiol 1993;264:H1998-H2006.

6. Amann K, Ritz E, Wiest G, Klaus G, Mall G. A role of parathyroid hormone for the activation of cardiac 
fibroblasts in uremia. J Am Soc Nephrol 1994;4:18141819.

7. Sonician M, Parissis JT. Cardiovascular diseases and hemodialysis: novel strategies for diagnosis, prevention and treatment. Hellenic J Cardiol 2003;44:206-217.

8. Braunwald E, Fauci A, Kasper D. Harrison's principles of internal Medicine. 15th ed. New York: McGraw-Hill 2001.

9. Slinin Y, Foley RN, Collins AJ. Calcium, phosphorus, parathyroid hormone, and cardiovascular disease in hemodialysis patients: the USRDS waves 1, 3, and 4 study. Journal of the American Society of Nephrology. 2005;16(6):1788-93.

10. Nematollahi A, Tamadon MR, Irannejad P, Fouladgar M, Bahadoram M, Mardani S. Association of serum phosphorus, calcium and parathyroid hormone with echocardiographic findings in regular hemodialysis patients. Journal of Parathyroid Disease 2018;6(2):45.

11. Jalali F, Rezaei N, Namdar Z. Heart complication in patients with chronic kidney disease and on dialysis. $\mathrm{J}$ Babol Univ Med Sci 2002;5:44-9.

12. Avila-Diaz M, Mora-Villalpando C, Prado-Uribe Mdel C, Orihuela-Rodriguez O, Villegas-Antelo E, GomezNoriega AM et al. De novo development of heart valve calcification in incident peritoneal dialysis patients. Arch Med Res 2013;44:638-44. doi: 10.1016/j.arcmed.2013.10.015.

13. Hsu $\mathrm{CH}$. Are we mismanaging calcium and phosphate metabolism in renal failure? Am J Kidney Dis 1997;29:641-649.

14. Delmez JA, Slatopolsky E. Hyperphosphatemia: Its consequences and treatment in patients with chronic renal disease. Am J Kidney Dis 1992;19:303-317.

15. Zuccheli P, Santoro A. Inorganic phosphate removal during different dialytic procedures. Int J Artif Organs 1987; 10:173-178.

16. Haas T, Hillion D, Dongradi G. Phosphate kinetics in dialysis patients. Nephrol Dial Transplant 1991;6(suppl 2):108-113

17. Chauveau P, Poignet JL, Kuno T, Bonete R, Kerebrun A, Naret $\mathrm{C}$ et al. Phosphate removal rate: A comparative study of five high flux dialyzers. Nephrol Dial Transplant 1991;6(suppl 2):114-115.

18. Desoi CA, Umans JG. Phosphate kinetics during high flux hemodialysis. J Am Soc Nephrol 1993;4:12141218.

19. Mousavi Movahed SM, Tabaraie Y, Alipour Nodoushan KH, Zakarianejad M. Relationship between calcium, phosphorous and parathoromone with calcification of heart valves in dialyzed patients in Qom, 2006-2007. Qom Uni Med Sci J 2008;2:21-7.

20. Block GA, Hulbert-Shearon TE, Levin NW, Port FK. Association of serum phosphorus and calcium $\mathrm{x}$ phosphate product with mortality risk in chronic hemodialysis patients: a national study. Am J Kidney Dis 1998;31:607-17. 